\title{
EFFISIENSI EKONOMI PEMANFAATAN HIJAUAN PAKAN PADA USAHA TERNAK SAPI DI KABUPATEN BOLAANG MONGONDOW SELATAN
}

\author{
Wantasen, E., Stevy, P. Pangemanan, Selvie. D. Anis, S. Dalie danF.N.S. Oroh \\ Fakultas Peternakan Universitas SamRatulangi \\ Email: erwinwantsen@yahoo.co.id
}

\begin{abstract}
ABSTRAK
Penelitian ini bertujuan untuk mengetahui pengaruh penggunaan biaya pakan hijauan dan tenaga kerja terhadap nilai produksi ternak sapi di Kabupaten Bolaang Mongondow Selatan dan mengetahui efiensi ekonomi penggunaan hijauan pakan terhadap nilai produksi ternak sapi di Kabupaten Bolaang Mongondow Selatan. Penelitian dilakukan dengan menggunakan metode survey terhadap peternak sapi. Sampel wilayah dipilih secara purposive berdasarkan jumlah populasi ternak sapi terbanyak dan terpilih Kecamatan Pinolosian. Sampel desa dipilih secara purposive dengan kriteria jumlah populasi ternak sapi terbanyak yaitu desa Pinolosian. Selanjutnya dari populasi Peternak sapi yang berpengalaman minimal 2 tahun dipilih secara acak sebanyak 30 peternak. Analisis data menggunakan fungsi produksi Cobb-Douglas untuk melihat pengaruh biaya hijauan pakan dan factor produksi tenaga kerja terhadap nilai produksi ternak sapi. Selanjutnya analisis efisiensi ekonomi dengan membandingkan Nilai Produk Marginal (NPM) dengan Biaya Faktor Marginal (BFM) hijauan dan tenaga kerja. Penggunaan hijauan pakan dikatakan efisien jika memenuhi syarat NPM $=$ BFM, jika NPM $>$ BFM belum efisien dan NPM $<$ BFM tidak efisien. Hasil penelitian menunjukkan rata-rata kenaikan nilai Produksi ternak sapi (NPM )yang dimilik ipeternak dalam setahun Rp.7.965.377 biaya factor marginal hijauan pakan sebesar Rp3·360.725 dan biaya faktor marginal tenaga kerja sebesar Rp. 1.894.885. Pakan hijauan memberikan pengaruh nyata terhadap nilai produksi ternak sapi dengan koefisien o,688 (P $<$.05) sedangkan faktor tenaga kerja member pengaruh nyata terhadap nilai produksi ternak sapi dengan koefisien 0,127 $(\mathrm{P}<.05)$ Perbandingan nilai produk marginal dan biaya pakan hijauan sebesar1,630 yang berarti penggunaan pakan hijauan belum optimal. Penggunaan tenaga kerja pada usaha ternak sapi belum optimal dengan perbandingan nilai produk marginal dan biaya pakan sebesar 1,847. Hasil penelitian menunjukkan bahwa dari sisi pakan hijauan maka nilai produksi ternak sapi di Kabupaten Bolaang Mongondow Selatan masih dapat ditingkatkan karena penggunaan pakan hijauan belum optimal.
\end{abstract}

\section{Kata kunci: ternak sapi, hijauan pakan, optimal}

\section{PENDAHULUAN}

Peternakan sapi di Indonesia umumnya berada dalam sistem usaha tani rumah tangga. Hampir sebagian besar usaha ternak sapi dilakukan oleh petani atau peternak dengan skala usaha kecil. Rumah tangga petani sebaga iprodusen produk pertanian secara umum, berada dalam skala usaha kecil, tidak mampu memenuhi kebutuhan konsumsi sehingga membutuhkan sumber penerimaan lain dari off farm atau non farm. Sumber penerimaan lain yang menjadi salah satu komponen pendukung usaha tani adalah ternak sapi. Ternak sapi merupakan pilihan utama bagi petani (jika mereka memiliki modal yang cukup) dijadikan sebagai tabungan, investasi atau penyedia modal usaha terutama usaha tani subsisten dimana kebijakan pengembangan ternak sapi meliputi intensifikasi dan ekstensifikasi (Yusdjadan Ilham 2007; Wantasen dkk, 2014; Tumewu, dkk, 2014).

Kabupaten Bolaang Mongondow Selatan merupakan salah satu wilayah pengembangan ternak sapi di Sulawesi Utara berdasarkan potensi alam dan budaya tani yang dimiliki masyarakat. Data dari Badan Pusat Statistik Kabupaten Bolaang Mongondow Selatan (2015) bahwa populasi ternak sapi potong sejak tahun 2013-2015 berturut-turut adalah 3.687 ekor, 4.214 ekor dan 4.973 ekor. Lokasi penyebaran ternak sapi potong terdapat di Kecamatan Pinolosian dan Kecamatan Bolaang Uki. Namun demikian populasi terbanyak terdapatdi Kecamatan Pinolosian sebesar 1.526 ekor. Penyebaran tersebut didukung oleh luasnya lahan penghasil hijauan makanan ternak yaitu 18.365 ha (BPS, Bolsel2015).

Usaha ternak sapi potong dikatakan berhasil jika produksi yang dihasilkan optimal, sedangkan produksi dikatakan optimal jika penggunaan faktor produksi dilakukan seefisien mungkin. Umumnya usaha ternak di Kabupaten Bolaang Mongondow Selatan masih dilakukan secara tradisional dengam ciri sebagai usaha sampingan, skala pemeliharaan kecil dan produktivitas yang rendah. Menurut Kalangi (2014) produktivitas ternak sapi dapat ditingkatkan dengan memperbaiki 
efisiensi usaha secara berkesinambungan. Paternak sapi di wilayah Kabupaten Bolaang Mongondow selatan rata-rata memelihara sapi secara ekstensif yaitu ternak sapi dilepas disekitar perkebunan kelapa atau disekitar lahan pertanian dan hutan. Hal ini dilakukan karena usaha ternak sapi belum menjadi sumber pendapatan utama keluarga petani. Ternak sapi dibiarkan merumput disekitar desa dengan rumput lapangan atau hijauan berkualitas rendah yang tersedia di sekitar perkebunan kelapa. Dalam sehari ternak sapi dipindahkan lokasi merumputnya sebanyak 2-3 kali. Peternak belum memanfaatkan hijauan pakan yang berasal dari rumput yang berkualitas seperti rumput gajah mini ataupun pakan yang diawetkan seperti amoniasi dan silase, padahal wilayah Kabupaten Bolaang Mongondow selatan memiliki lahan padi sawah, jagung dan kedelai yang jeraminya dapat dijadikan pakan berkualitas dengan luas 7.127 ha. Kondisi tersebut merupakan potensi yang dapat dimanfaatkan oleh peternak sapi dalam upaya meningkatkan produktivitas ternak yang dimiliki karena pakan adalah salah satu faktor pendukung terpenting dalam pengembangan usaha ternak sapi.

Oleh karena itu penelitian ini diharapkan dapat memberikan informasi berkaitan dengan penggunaan factor produksi hijauan pakan pada usaha ternak sapi di wilayah Kabupaten Bolaang Mongondow Selatan. Selanjutnya akan dianalisis tingkat efisiensi penggunaan hijauan pakan pada usaha ternak sapi potong di wilayah ini. Manfaat dari diketahuinya tingkat efisiensi ekonomi dari pakan hijauan akan bermanfaat bagi petani untuk melakukan perencanaan realokasi factor prioduksi pakan hijauan dalam usaha ternak sapi.

\section{METODE PENELITIAN}

Penelitian dilaksanakan dengan menggunakan metode survey terhadap keluarga peternak sapi potong di Kabupaten Bolaang Mongondow Selatan. Pengumpulan data primer dan data sekunder dilakukan pada bulan Oktober - Desember 2015. Penentuan sample dilakukan dengan metode multi stage sampling yaitu penentuan sampel kecamatan, sampel desa dan sampel peternak secara berjenjang. Kecamatan Pinolosian terpilih sebagai sampel kecamatan dengan pertimbangan memiliki populasi ternak sapi terbanyak. Selanjutnya dipilih desa Pinolosian sebagai sampel desa dengan populasi terbanyak dan sample responden dipilih sebanyak 30 peternak dengan criteria memiliki ternak minimal 2 ekor sapi dewasa dan berpengalaman minimal 2 tahun memelihara sapi. Analisis data menggunakan analisis efisiensi ekonomi (Debertin, 1986; Arifah,
2006)) dimana nilai produk marginal faktor produksi sama dengan harga factor produksi dengan formulasi:

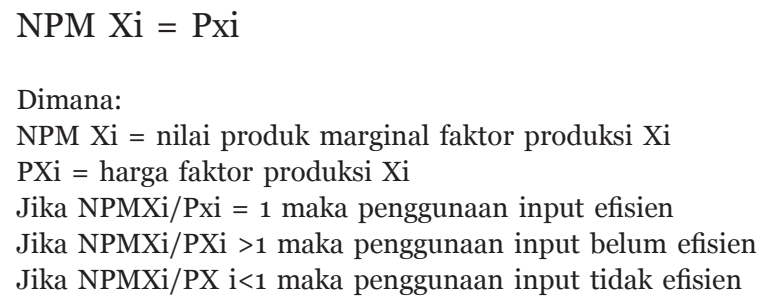

Untuk mengetahui pengaruh penggunaan pakan dan tenaga kerja terhadap nilai produksi ternak sapi potong maka digunakan model fungsi produksi Cobb doglass yang ditransformasikan kedalam bentuk logaritma natural:

$$
\begin{aligned}
& \text { Ln Y= Ln ao+ b1LnX1+ b2LnX2 +ei } \\
& \text { Dimana } \\
& \mathrm{Y}=\text { nilai produksi ternak sapi dalam setahun (Rp/tahun) } \\
& \mathrm{X} 1=\text { biaya hijauan (Rp/tahun) } \\
& \mathrm{X} 2 \text { = Biaya tenaga kerja (Rp/tahun) } \\
& \text { ao = koefisien intersep } \\
& \text { ei = faktorpengganggu }
\end{aligned}
$$

\section{HASIL DAN PEMBAHASAN}

\section{Nilai Produksi Ternak Sapi Potong dan Biaya Produksi}

Produksi ternak sapi dihitung dengan menggunakan formulasi peningkatan nilai ternak sapi selama pemeliharaan satu tahun berupa pertambahan anak sapi yang dilahirkan, pertumbuhan ternak dari pedet menjadi ternak muda dan menjadi dewasa yang dihitung pada akhir tahun pemeliharaan ditambah dengan penjualan ternak dikurangi dengan pembelian ternak selama setahun. Biaya produksi adalah biaya yang dikeluarkan oleh peternak dalam penelitian ini berupa biaya pakan hijauan dan biaya tenaga kerja. Biaya pakan hijauan dihitung dengan menggunakan pendekatan upah TK rumah tangga memberi pakan sedangkan biaya tenaga kerja pada usaha sapi dihitung dengan pendekatan upah yang dikeluarkan rumah tangga peternak pada aktivitas memelihara sapi kecuali aktivitas member pakan hijauan yang dihitung sebagai biaya pakan hijauan. Aktivitas memelihara sapi di daerah penelitian meliputi mengawinkan sapi baik dengan inseminasi maupun kawin alam, mengandangkan, memandikan,,mengolah kotoran sapi menjadi pupuk, dan menjual ternak.

Hasil penelitian menunjukkan bahwa rata rata kenaikan nilai produksi ternak sapi selama setahun Rp7.965.377. Kenaikan nilai produksi tertinggi adalah Rp32,467.872 sedangkan nilai terendah adalah Rp5.117.60o. Rata-rata biaya pakan hijauan oleh 
peternak sapi adalah Rp3.360.725. Biaya tertinggi sebesar Rp4.855.690 dan biaya terendah adalah Rp 1.864.335. Perbedaan biaya pakan disebabkan perbedaan lokasi pengambilan hijauan dan jumlah ternak yang diberi makan. Perbedaan nilai produksi ternak pertahun disebabkan perbedaan kondisi ternak dimana ternak yang lebih kecil nilainya lebih rendah, perubahan jumlah ternak yang dipelihara, jumlah yang dijual dan harga ternak sapi. Rata-rata biaya tenaga kerja pertahun dalam memelihara sapi adalah Rp 1.894.885. Biaya tertinggi sebesar Rp2.743.218, sedangkan biaya terendah adalah Rp1.325.346. Perbedaan ini disebabkan karena perbedaan frekuensi memandikan sapi, mengawinkan ternak, mengolah kompos kotoran sapi dan penjualan ternak. Hasil penelitian sejalan dengan Mastuti dkk (2015) bahwa rata-rata biaya pakan hijauan ternak sapi di Kabupaten Banjar Negara sebesar Rp.2.028.487/tahun dengan nilai produksi ternak pertahun sebesar Rp5.350.ooo.

Tabel 1. Kenaikan Nilai Ternak dan Biaya Produksi Usaha Ternak Sapi di Kabupaten Bolaang Mongondow Selatan

\begin{tabular}{lrcr}
\hline $\begin{array}{c}\text { Parameter } \\
\text { deskriptif }\end{array}$ & $\begin{array}{c}\text { Kenaikan nilai } \\
\text { ternak sapi (Rp/ } \\
\text { Thn) }\end{array}$ & $\begin{array}{c}\text { Biaya pakan } \\
\text { hijauan (Rp/Thn) }\end{array}$ & $\begin{array}{c}\text { Biaya tenaga kerja } \\
\text { (Rp/Thn) }\end{array}$ \\
\hline Ratarata & 7.965 .377 & 3.360 .725 & 1.894 .885 \\
Maksimum & $32,467.872$ & 4.855 .690 & 2.743 .218 \\
Minimum & 5.117 .600 & 1.864 .335 & 1.325 .346 \\
Std Deviasi & $3.117 .654,36$ & $1.215 .220,67$ & $736.355,20$ \\
\hline
\end{tabular}

Sumber: data diolah (2016)

\section{Analisis Nilai Produksi Ternak Sapi dan Efisien- si Ekonomi Hijauan Pakan}

Hasil penelitian menunjukkan bahwa biaya pakan hijauan memberikan pengaruh nyata terhadap nilai produksi ternak sapi dengan koefisien o,688 $(\mathrm{P}<.05)$ sedangkan factor tenaga kerja memberi pengaruh nyata terhadap nilai produksi ternak sapi dengan koefisien $0,127(\mathrm{P}<.05)$. Nilai koefisien determinasi $\left(\mathrm{R}^{2}\right)$ sebesar 0,7956 artinya79,56\% variasi nilai produksi ternak sapi dipengaruhi oleh variasi biaya pakan hijauan dan biaya tenaga kerja keluarga peternak sedangkan 20,44\% dipengaruhi oleh factor lain diluar model yang dibangun yang dapat berupa aspek sosial, teknologi, lingkungan atau puna spek ekonomi lainnya. Nilai F hitung sebesar 38,433 yang secara statistic signifikan pada tingkat kepercayaan 95\% menunjukkan bahwa secara bersama-sama variable biaya pakan hijauan dan biaya tenaga kerja berpengaruh nyata pada nilai produks iternak sapi di Kabupaten Bolaang Mongondow Selatan.

Hasil analisis regresi pada Tabel 2 menunjukkan bahwa secara parsial faktor biaya pakan hijauan berpengaruh nyata $(\mathrm{P}<.05)$ terhadap nilai produksi ternak sapi dengan koefisien sebesar 0,688 yang artinya jika biaya pakan meningkat 1 persen maka nilai
Tabel 2. Hasil Estimasi Nilai Produksi Ternak Sapi Potong

\begin{tabular}{lccc}
\hline \multicolumn{1}{c}{ Parameter } & $\begin{array}{c}\text { Coeffisien } \\
\text { regresi }\end{array}$ & t-Stat & Sig \\
\hline Konstanta & 2,371 & 1,086 & 0,127 \\
Biaya pakan hijauan (X1) & 0,688 & 4,225 & 0,048 \\
Biaya tenaga kerja (X2) & 0,127 & 3,117 & 0,052 \\
RSquare $\left(\mathrm{R}^{2}\right)$ & 0,7956 & & \\
F hit. & 38,433 & & \\
Sig. F & 0,0063 & & \\
\hline
\end{tabular}

Sumber: Data diolah (2016)

produksi ternak sapi akan meningkat o,688 persen. Hal ini disebabkan peningkatan biaya pakan hijauan berarti ada peningkatan penggunaan hijauan berkaitan dengan jumlah ternak yang dimiliki. Semakin banyak ternak yang dimiliki maka semakin banyak waktu yang dibutuhkan peternak untuk memberi makan sehingga berdampak pada biaya pakan hijauan. Lokasi mencari pakan hijauan yang jauh dari lokasi pemukiman akan mengakibatkan biaya pakan semakin bertambah. Hal ini dilakukan peternak untuk menjaga kuantitas dan kualitas pakan yang diberikan. Peternak juga memberikan daun jagung dan daun ubi jalar sebagai pakan ternak. Hal ini sejalan dengan Enisa dkk (2006) bahwa apabila pemberian pakan tidak memenuhi persyaratan kuantitas dan kualitas, maka produksi dan nilai tambah yang tinggi tidak akan tercapai. Peningkatan biaya pakan akan meningkatkan nilai produksi ternak sapi sehingga nilai produksi akhirnya akan menutupi besarnya biaya pakan hijauan (Hanafie, 2010).

Faktor tenaga kerja berpengaruh nyata pada nilai produksi ternak sapi $(\mathrm{P}<.05)$ dengan nilai koefisen parameter 0,127. Hal ini berarti jika biaya tenaga kerja meningkat 1 persen maka nilai produksi ternak sapi meningkat 0,127 persen. Penggunaan tenaga kerja keluarga berpengaruh terhadap nilai produksi ternak sapi karena setiap hari peternak mengurus ternaknya dengan baik seperti member makan dan minum, memandikan, mengawinkan, mengolah kotoran sapi, menjual, member obat jika sakit sehingga ternak sapi memiliki penampilan fisik yang baik sebagai tenaga kerja di kebun dan kotorannya digunakan sebagai pupuk di lahan usahatani sehingga nilainya semakin tinggi. Peternak sangat memperhatikan lokasi merumput ternak sehingga lokasi merumput akan dipindahkan 2-3 kali setiap hari agar sapi tetap memperoleh rumput dengan jumlah yang cukup karena bila ternak hanya dibiarkan merumput sendiri maka kebutuhan pakannya tidak terkontrol dan akibatnya sapi menjadi kurus dan nilainya menurun. Hasil penelitian sejalan dengan Purnomo (2010) dan Kalangi (2008) bahwa produksi dan pendapatan usaha sapi potong dipengaruhi oleh jumlah sapi potong, tenaga kerja keluarga , pendidikan peternak 
dan jumlah pakan konsentrat.

Hasil analisa efisiensi ekonomi menunjukkan bahwa nilai efisiensi ekonomi pakan hijauan sebesar 1,630 sedangkan efisiensi ekonomi faktor produksi tenaga kerja keluarga sebesar1,847. Penggunan Input produksi hijauan pakan belum efisien karena bernilai lebih besar dari satu yang berarti penggunaan hijauan masih belum optimal dan masih dapat ditingkatkan disebabkan kualitas pakan yang diberikan masih beragam sehingga pemberiannya belum efisien. Hal ini sejalan dengan pendapat Supratman dan Iwan (2001) bahwa produktivitas ternak akan maksimal jika diberikan pakan yang mencukupi baik kuantitas dan kualitasnya demikian pula hasil penelitian menunjukkan hal yang sama dengan Sidauruk dkk (2010).

\section{SIMPULAN}

Biaya pakan hijauan dan biaya tenaga kerja keluarga peternak berpengaruh nyata terhadap peningkatan nilai produksi ternak sapi di Kabupaten Bolaang Mongondow Selatan. Penggunaan pakan hijauan dan tenaga kerja keluarga masih dapat diperbaiki efisiensinya karena peternak belum memanfaatkan hijauan pakan secara optimal.

\section{REFERENSI}

Arifah, E.N. 2006. Analisis efsisiensi ekonomi penggunaan factor produksi pada usahatani jagung varitas bisi-2 di Kabupaten Bantul. Buletin Peternakan Vol 18(2):43-47

BPS Bolsel. 2015. Bolaang Mongondow Selatan Dalam Angka. Kantor Statistik Kabupaten Bolaang Mongomdow Selatan.

Hanafie, R., 2010. Pengantar Ekonomi Pertanian. C.V.Andi Offset, Jogyakarta

Kalangi, J.K.J. 2008. Analisis usaha ternak sapi potong Di Kecamatan Kawangkoan. Jurnal Zootek (26):1-11
Kalangi, L.S. 2014. Analisis Efisiensi Ekonomi Usaha Perkembangbiakan Ternak Sapi Potong Rakyat di Propinsi Jawa Timur. Disertasi Sekolah Pasca Sarjana IPB, Bogor.

Mastuti, S. Y.N. Wakhidati, O.E. Djatmiko. Efisiensi penggunaan Hijauan pada Usaha Sapi Potong Di Kabupaten Banjar Negara. Proseeding Seminar Nasional Strategi Pengembangan Hijauan Pakan Lokal Berkualitas Untuk Peningkatan MutuTernak. ISBN978-602-1004-16-6:101-105.

Purnomo, S. 2010. Model Simulasi Kebijakan Pengembangan Pendapatan Ekonomi Rumah Tangga Peternak Sapi Potong (Studi Kasus di Kecamatan Damsol Kabupaten Donggala). Disertasi.Universitas Brawijaya Program Pasca Sarjana Malang.

Sidauruk, L., Cyrilla L, Atmakusuma. J. 2010. Analisis Efisiensi Pola Usaha Sapi Potong di Bekasi, Jawa Barat (Kasus PT Lembu Jantan Perkasa) Media Peternakan 24(1):128-135

Supratman dan Iwan. 2001. Manajemen Pakan Sapi Potong. Pelatihan Wirausaha Feedlot Sapi Potong. Fakultas Peternakan UNPAD, Bandung

Tumewu, J.M., V.V.J. Panelewen, A.D.P. Mirah. 2014. Analisis usahatani terpadu sapi potong dan padi sawah pada kelompok tani-Keong Mas Kecamatan Sangkub Kabupaten Bolaang Mongondow Utara. Zootek Vol34(2): 1-9

Wantasen, E., S.D. Anis, S. Daliedan, F.N.S Oroh. 2014. Analisis Potensi Pengembangan Ternak Potong Di Kabupaten Bolaangmongondow Selatan. Laporan Penelitian Kerjasama Bapeda Pemkab Bolaangmongondow Selatan dan Fakultas Peternakan Unsrat

Yusdja,Y.dan N.Ilham. 2007. Suatu gagasan tentang peternakan masa depan dan strategi mewujudkannya. ForumPenelitian Agro Ekonomi25(1):19-28 